Quim. Nova, Vol. 34, No. 9, 1496-1500, 2011

\title{
INVENTÁRIO DE EMISSÃO DE FONTES VEICULARES DA REGIÃO METROPOLITANA DE CAMPINAS, SÃO
}

\section{PAULO}

\author{
Ana Cláudia Ueda* e Edson Tomaz \\ Faculdade de Engenharia Química, Universidade Estadual de Campinas, Cidade Universitária “Zeferino Vaz”, Av. Albert Einstein, \\ 500, 13083-852 Campinas - SP, Brasil
}

Recebido em 16/9/10; aceito em 6/5/11; publicado na web em 17/6/11

\begin{abstract}
VEHICULAR EMISSIONS INVENTORY FROM METROPOLITAN REGION OF CAMPINAS (MRC), SP, BRAZIL. The degradation of air quality in great urban centers is noted by frequent critical episodes of air pollution and public health issues, and vehicles are a great source of pollutant emissions, mainly derived from combustion processes. A database is needed to direct mitigation of emissions. The main objective of this work is to present it as an emissions inventory. The results show that vehicular sources of $\mathrm{CO}, \mathrm{HC}$ and $\mathrm{NO}_{\mathrm{x}}$ represent over $75 \%$ of total emissions in the MRC. Besides, the proposed methodology presented results consistent with the literature.
\end{abstract}

Keywords: emissions inventory; vehicular sources; atmospheric pollutants.

\section{INTRODUÇÃO}

Nas últimas décadas tem se dado grande destaque à degradação da qualidade do ar em grandes centros urbanos. As principais fontes de emissões em regiões urbanas podem ser fixas (indústrias, queimadas, etc.) ou móveis (veículos automotores, aviões, etc.), sendo que o elevado número de veículos nas cidades torna as emissões destas fontes móveis responsáveis pela maior parte das emissões. No Brasil, o número de veículos foi de 51.464.103, em 2008. A frota veicular do Estado de São Paulo corresponde a 32,7\% da frota brasileira, sendo que a frota da Região Metropolitana de Campinas (RMC) corresponde a 1.336 .603 veículos. $^{1}$

Os principais poluentes atmosféricos emitidos por fontes móveis são monóxido de carbono $(\mathrm{CO})$, óxidos de nitrogênio $\left(\mathrm{NO}_{\mathrm{x}}\right)$, dióxido de enxofre $\left(\mathrm{SO}_{2}\right)$, material particulado (MP) e hidrocarbonetos (HC). O monóxido de carbono, os óxidos de nitrogênio e o material particulado são produtos da combustão em motores a combustão interna. Os hidrocarbonetos são emitidos pelo escapamento dos veículos e, também, pela evaporação dos combustíveis e dos óleos lubrificantes. O dióxido de enxofre está relacionado principalmente à presença de enxofre no combustível. Alguns poluentes, como monóxido de carbono (CO), ozônio $\left(\mathrm{O}_{3}\right)$, material particulado (MP), aldeídos ( $\mathrm{RCHO})$, óxido nítrico $\left(\mathrm{NO}_{2}\right)$ e hidrocarbonetos $(\mathrm{HC})$, como benzeno, 1,3-butadieno, benzopireno, têm efeitos adversos à saúde humana bem conhecidos e estão relacionados a doenças respiratórias, como asma, à maior incidência de câncer, doenças cardiovasculares, problemas neurológicos e de reprodução. ${ }^{2}$

O inventário de emissões é uma ferramenta de grande utilidade no estudo da poluição urbana, pois permite a identificação de fontes predominantes de emissão e, também, o estudo de tendências anuais de redução ou aumento de determinados poluentes na atmosfera. Além disso, com esta ferramenta é possível avaliar o progresso de metas de redução de emissões, sendo um importante instrumento de avaliação estratégica de monitoramento e controle da qualidade do ar. No Brasil, principalmente as agências estaduais de controle e planejamento

*e-mail: ana.ueda@gmail.com ambiental, bem como centros de pesquisa, vêm realizando este tipo de trabalho no intuito de quantificar as emissões atmosféricas nos grandes centros urbanos e identificar as principais fontes de poluição, de forma a propor medidas para sua mitigação. O inventário de emissões realizado em 2004 pela Fundação Estadual de Engenharia do Meio Ambiente (FEEMA), na Região Metropolitana do Rio de Janeiro, apontou que as emissões veiculares são responsáveis por $77 \%$ das emissões nesta região, também identificou as vias de maior tráfego e, consequentemente, de maiores emissões. ${ }^{3}$ Segundo Lyra, ${ }^{4}$ a Região Metropolitana de Salvador também possui as fontes veiculares como grandes contribuintes na degradação da qualidade do ar para alguns poluentes importantes, como $\mathrm{CO}, \mathrm{NO}_{\mathrm{x}}$, MP e COT (carbono orgânico total). A importância das emissões de fontes móveis também foi estudada na Região Metropolitana de Porto Alegre, onde se constatou que a maior parte dos veículos é movida a gasolina, a qual é responsável pela maioria das emissões de CO, aldeídos e hidrocarbonetos. Este estudo também apontou uma redução das emissões a partir da implantação do PROCONVE (Programa de Controle da Poluição do Ar por Veículos Automotores) em 1986 e com as grandes inovações tecnológicas que ocorreram entre 1992 e 1997..$^{5}$ Entre as tecnologias que passaram a ser utilizadas pode-se citar o uso de catalisadores automotivos, que atenderam de maneira eficiente às exigências legais para redução das emissões, principalmente de $\mathrm{CO}, \mathrm{NO}_{\mathrm{x}}$ e $\mathrm{COV}$ (compostos orgânicos voláteis). No entanto, no Brasil, ainda existe o desafio de reduzir as emissões de compostos oxigenados (alcoóis, aldeídos e ácidos carboxílicos) devido à utilização de etanol. ${ }^{6}$

Desta forma, o principal objetivo deste trabalho foi a elaboração do inventário de emissões veiculares da RMC, que possa ser útil para a proposição de medidas de controle e de prevenção à degradação da qualidade do ar, bem como medidas de controle de emissões veiculares e de programas de inspeção e manutenção de veículos.

\section{PARTE EXPERIMENTAL}

Região de estudo

A Região Metropolitana de Campinas (RMC) é composta por 
19 municípios, correspondendo a $14,9 \%$ da população estadual e a 7,94\% da frota de veículos do estado de São Paulo, sendo a região de maior expressão industrial e econômica do interior do estado. As principais vantagens apresentadas pela região são boa infra-estrutura de transportes devido a importantes rodovias; proximidade da Região Metropolitana de São Paulo; presença de importantes centros de pesquisa, como UNICAMP, Fundação Centro Tecnológico para a Informática - CTI, Centro de Pesquisa e Desenvolvimento - CPqD, Instituto Agronômico de Campinas - IAC, Instituto Tecnológico de Alimentos - Ital e o Laboratório Nacional de Luz Sincrotron - LNLS e, mão-de-obra qualificada. Estes fatores proporcionaram à região o desenvolvimento de um forte parque industrial, contando com importantes indústrias dos ramos petroquímico, têxtil, alimentício, automotivo, metalúrgico, farmacêutico, entre outras. ${ }^{7}$ Portanto, a região é contemplada tanto com expressivas emissões veiculares quanto industriais.

\section{Metodologia}

A abordagem utilizada na realização deste inventário foi bottomup, baseada nos fatores médios de emissão para veículos novos da Agência Ambiental do Estado de São Paulo - CETESB, usados na elaboração dos seus relatórios anuais de qualidade do ar. Além disso, também foram levados em consideração a distribuição da idade da frota, o fator de deterioração e a variação da quilometragem média percorrida em função da idade do veículo, bem como a diferenciação por tipo de combustível utilizado (etanol, gasolina, diesel e bicombustível). A Figura 1 mostra as etapas de cálculo envolvidas no método.

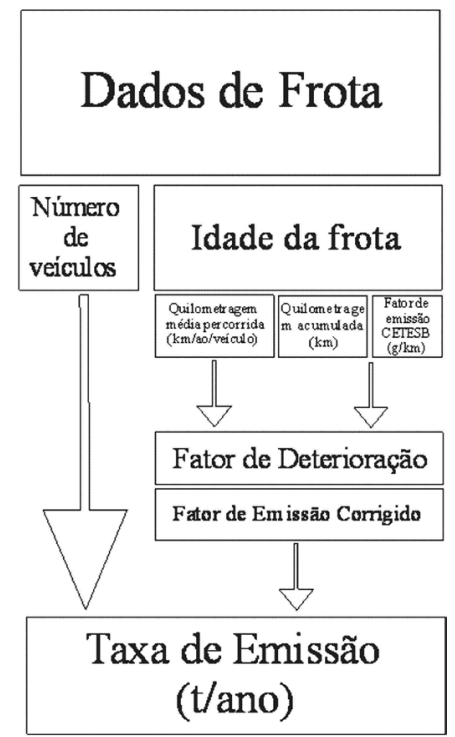

Figura 1. Esquema da metodologia de cálculo para obtenção das taxas de emissão anuais

As taxas de emissão anuais foram calculadas para os seguintes poluentes: monóxido de carbono (CO), hidrocarbonetos (HC), óxidos de nitrogênio $\left(\mathrm{NO}_{\mathrm{x}}\right)$, material particulado (MP) e aldeídos ( $\left.\mathrm{RCHO}\right)$, sendo que o MP foi calculado apenas para veículos a diesel e o RCHO para veículos a etanol. Os valores calculados das taxas de emissão foram comparados com os valores publicados no Relatório de Qualidade do Ar da CETESB de 2008 e também com o inventário de emissões industriais da região de estudo. ${ }^{9}$

Tendo em vista a indisponibilidade de dados de distribuição da idade da frota para a RMC, esta foi considerada similar à Região Metropolitana de São Paulo, cujos dados podem ser obtidos do Departamento Estadual de Trânsito de São Paulo. ${ }^{10}$ Esta aproximação é bastante razoável devido à semelhança do perfil sócio-econômico das duas regiões.

\section{Dados da frota}

Com relação às categorias de veículos que compõem a frota, utilizou-se a seguinte classificação, a partir dos tipos de veículos definidos pelo IBGE: ${ }^{1}$ automóveis, veículos comerciais leves (microônibus e caminhonetes), motocicletas (motocicletas e motonetas) e veículos pesados (caminhões, caminhões trator, ônibus e tratores de roda). O número de veículos de cada categoria foi obtido aplicando-se a participação percentual de cada uma delas ao número total veículos da frota, para cada ano de fabricação.

\section{Automóveis}

Foram considerados automóveis movidos a gasolina, etanol e bicombustível (gasolina e etanol). Para cada tipo de combustível foi estimada a distribuição percentual dos automóveis por ano de fabricação, baseada no número de veículos licenciados em cada ano. ${ }^{11}$

Os fatores de emissão calculados (FE corrigidos) foram considerados como sendo os fatores médios de emissão de veículos leves novos do PROCONVE ${ }^{12}$ multiplicados por um fator de deterioração (FD), que depende da quilometragem acumulada do veículo.

Para calcular a quilometragem acumulada de acordo com a idade do veículo foi utilizada a Equação 1: ${ }^{13}$

$$
y=-367,87 x^{2}+13644 x
$$

na qual: $\mathrm{y}=$ quilometragem acumulada; $\mathrm{x}$ = idade do veículo.

Os fatores de deterioração para cada poluente foram calculados pelas Equações 2 e $3: 14,15$

$$
\begin{aligned}
\mathrm{FD}_{\mathrm{CO}} & =\frac{56,34+2,55 \mathrm{Y}}{56,34} \\
\mathrm{FD}_{\mathrm{HC}} & =\frac{4,43+0,25 \mathrm{Y}}{4,43}
\end{aligned}
$$

sendo $\mathrm{FD}_{\mathrm{CO}}$ o fator de deterioração para monóxido de carbono; $\mathrm{FD}_{\mathrm{HC}}$, o fator de deterioração para hidrocarbonetos e Y dado pela Equação 4:

$$
\mathrm{Y}=\frac{\mathrm{y}}{1,61 \times 10^{4}}
$$

na qual y é a quilometragem acumulada calculada na Equação 1.

$\mathrm{O}$ valor de $\mathrm{Y}$ é constante e igual a 6,27 para veículos com mais de $100.000 \mathrm{~km}$ percorridos e para veículos com idade maior ou igual a 27 anos foi considerada uma quilometragem acumulada máxima igual a $100.000 \mathrm{~km}$. Além disso, os fatores de deterioração para outros poluentes, como $\mathrm{NO}_{x}$, MP e RCHO, foram considerados iguais a 1,0. ${ }^{14,15}$ A quilometragem média anual percorrida, para automóveis, foi considerada igual a $20.000 \mathrm{~km}$ no primeiro ano de uso do veículo e uma taxa de redução anual de $2 \%$ com o aumento da idade. ${ }^{13}$ Assim, para cada idade da frota considerada foi multiplicado o valor da quilometragem média anual percorrida, o fator de emissão corrigido com o fator de deterioração e o número de veículos, resultando na taxa de emissão. Somando os valores da taxa de emissão para cada idade obteve-se a taxa de emissão total do poluente para cada tipo de combustível considerado (Equação 5):

Taxa de Emissão Total $=\sum_{\text {idade }} n^{\circ}$ de veículos $\times$ km média anual $\times$ FE corrigido

Veículos comerciais leves

Foram considerados como veículos comerciais leves: micro- 
ônibus e caminhonetes. A partir do Anuário Estatístico da ANFAVEA (Associação Nacional dos Fabricantes de Veículos Automotores) ${ }^{11}$ foi obtida a distribuição etária para este tipo de veículo, bem como a distribuição por tipo de combustível, entre os quais foram considerados movidos a gasolina, etanol, diesel e bicombustível. Para os veículos movidos a gasolina, etanol e bicombustível foram considerados os fatores de emissão iguais aos de veículos leves e para veículos a diesel foram considerados fatores de emissão iguais a de veículos pesados.

A quilometragem acumulada e os fatores de deterioração para $\mathrm{CO}$ e HC foram calculados como descrito para os automóveis, a partir das Equações 1, 2, 3 e 4.

A frota de veículos comerciais leves é composta por $93,45 \%$ de caminhonetes e $6,55 \%$ de micro-ônibus. A quilometragem média percorrida das caminhonetes é similar à dos caminhões, enquanto dos micro-ônibus pode ser considerada igual à dos ônibus. Desta forma, foi calculada uma quilometragem média percorrida para esta categoria como uma média ponderada, fornecendo o valor aproximado de $38.250 \mathrm{~km} / \mathrm{ano}$.

A taxa total de emissão por tipo de poluente considerado também foi calculada pela Equação 5 .

\section{Veículos pesados}

Foram considerados como veículos pesados: ônibus, caminhões, caminhões trator e tratores de roda. Também foi considerado que todos os veículos desta categoria são movidos a diesel. Os fatores de emissão para estes veículos foram obtidos dos Relatórios de Qualidade do Ar da CETESB para o período de 2001 a $2005 .{ }^{8}$ Para o período anterior a 2001 foram considerados fatores de emissão iguais a 2001 e para períodos posteriores a 2005 foram considerados os fatores de emissão relacionados a 2005. A Tabela 1 mostra os fatores de emissão utilizados para veículos pesados.

Tabela 1. Fatores de emissão para veículos pesados em uso

\begin{tabular}{ccccc}
\hline \multirow{2}{*}{ Ano } & \multicolumn{4}{c}{ Fatores de emissão $(\mathrm{g} / \mathrm{km})$} \\
\cline { 2 - 5 } & $\mathrm{CO}$ & $\mathrm{HC}$ & $\mathrm{NO}_{\mathrm{x}}$ & $\mathrm{MP}$ \\
\hline 2001 & 17,80 & 2,90 & 13,00 & 0,81 \\
2002 & 17,80 & 2,90 & 13,00 & 0,81 \\
2003 & 17,80 & 2,90 & 13,00 & 0,81 \\
2004 & 15,60 & 2,48 & 11,17 & 0,62 \\
2005 & 15,00 & 2,36 & 10,74 & 0,57 \\
\hline
\end{tabular}

A quilometragem acumulada para veículos pesados também foi calculada utilizando-se a Equação 1 e a quilometragem média anual percorrida para o primeiro ano de uso foi considerada como a média ponderada da quilometragem média anual percorrida de caminhões (51.500 km/ano) e de ônibus (73.500 km/ano) com uma taxa de redução anual igual a $2 \% .^{13}$

Os fatores de deterioração utilizados para veículos pesados foram os mesmos que os utilizados para veículos leves, e calculados pelas Equações 2 a 4.

Para cada poluente foi calculada a taxa total de emissão pela Equação 5.

\section{Motocicletas}

Para motocicletas e motonetas foram utilizados fatores de emissão de motocicletas novas e similares ${ }^{9}$ de 2003 , considerando que todas possuem $150 \mathrm{cc}$ ou menos e são nacionais. A quilometragem média anual percorrida para o primeiro ano de uso foi considerada igual a $12.000 \mathrm{~km}^{14}$ e foi utilizada uma taxa de redução anual de $2 \% .^{13} \mathrm{~A}$ quilometragem acumulada também foi calculada pela Equação 1, bem como os fatores de deterioração pelas Equações 2 a 4 .
A Equação 5 foi utilizada para calcular a taxa total de emissão por tipo de poluente considerado.

\section{RESULTADOS}

De acordo com as categorias definidas, a distribuição da frota da RMC por tipo de veículo é dada por: 69,61\% de automóveis, $6,76 \%$ de veículos comerciais leves, 3,99\% de veículos pesados e 19,64\% de motocicletas.

Os resultados para a distribuição segundo o tipo de combustível são mostrados na Tabela 2.

Tabela 2. Distribuição dos veículos por tipo de combustível

\begin{tabular}{lcc}
\hline Tipo de combustível & $\mathrm{N}^{\text {o }}$ de veículos & $\%$ \\
\hline Gasolina & 942.262 & 70,50 \\
Etanol & 153.177 & 11,46 \\
Bicombustível & 163.657 & 12,24 \\
Diesel & 77.507 & 5,80 \\
Total & $\mathbf{1 . 3 3 6 . 6 0 3}$ & $\mathbf{1 0 0 , 0}$ \\
\hline
\end{tabular}

Como pode ser visto na Tabela 2, a predominância por tipo de combustível é de veículos movidos a gasolina, incluindo automóveis e motocicletas. Deve ser ressaltada também a expressividade dos veículos do tipo bicombustível que, mesmo sendo uma tecnologia comercialmente disponível desde 2003, já corresponde a 12,24\% dos veículos circulantes.

As emissões anuais de monóxido de carbono (CO), hidrocarbonetos $(\mathrm{HC})$, óxidos de nitrogênio $\left(\mathrm{NO}_{x}\right)$, aldeídos $(\mathrm{RCHO})$ e material particulado (MP), de acordo com a categoria de veículo e o tipo de combustível, estão apresentadas na Tabela 3.

Tabela 3. Emissões veiculares anuais dos poluentes na RMC

\begin{tabular}{lccccc}
\hline \multirow{2}{*}{ Categoria } & \multicolumn{5}{c}{ Emissões $\left(10^{3}\right.$ t/ano) } \\
\cline { 2 - 6 } Automóveis & $\mathrm{CO}$ & $\mathrm{HC}$ & $\mathrm{NO}_{\mathrm{x}}$ & $\mathrm{RCHO}$ & $\mathrm{MP}$ \\
$\quad$ gasolina & 109,85 & 11,16 & 4,78 & 0,17 & \\
$\quad$ etanol & 32,22 & 3,56 & 2,20 & 0,22 & \\
$\quad$ bicombustível & 1,53 & 0,35 & 0,23 & 0,04 & \\
Veículos comerciais leves & & & & & \\
$\quad$ gasolina & 17,55 & 1,76 & 0,69 & & \\
$\quad$ etanol & 4,09 & 0,46 & 0,29 & & \\
$\quad$ bicombustível & 0,18 & 0,04 & 0,03 & & \\
$\quad$ diesel & 15,34 & 2,59 & 9,22 & & 0,55 \\
Veículos pesados & 47,56 & 8,03 & 28,47 & & 1,71 \\
Motocicletas & 16,03 & 2,26 & 0,43 & & \\
\hline Total & $\mathbf{2 4 4 , 3 5}$ & $\mathbf{3 0 , 2 1}$ & $\mathbf{4 6 , 3 5}$ & $\mathbf{0 , 4 3}$ & $\mathbf{2 , 2 6}$ \\
\hline
\end{tabular}

A Tabela 3 mostra que as emissões de automóveis são as mais expressivas em termos de emissões veiculares, já que estes representam a maior parte da frota circulante. A frota de veículos comerciais leves também apresenta emissões consideráveis, apesar de ter um número de veículos reduzido em relação ao número de automóveis. Isto é devido, principalmente, à grande quilometragem média anual percorrida por esta categoria de veículo. As motocicletas são em grande número, mas não possuem emissões tão significativas. Os veículos pesados são os maiores emissores de $\mathrm{NO}_{\mathrm{x}}$ entre os veículos. 
A comparação entre as emissões veiculares calculadas neste trabalho e as emissões publicadas pela CETESB, ${ }^{9}$ classificadas por tipo de combustível, é apresentada nas Figuras 2, 3 e 4.

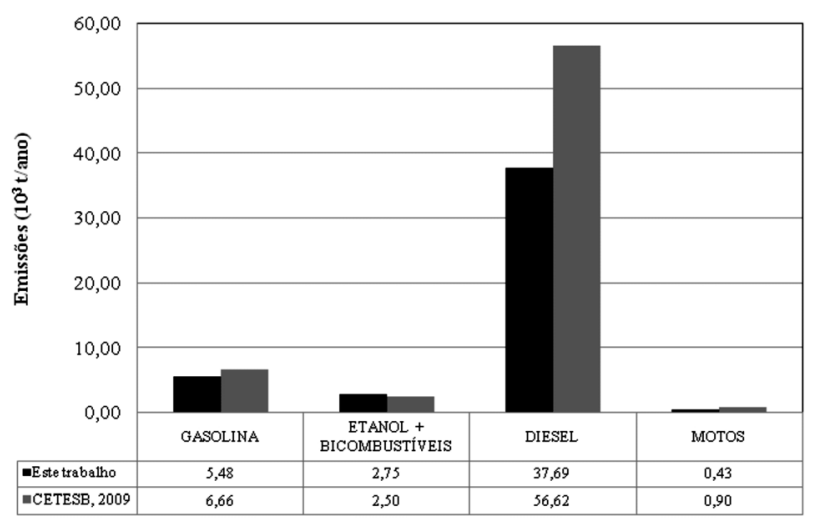

Figura 2. Comparativo das emissões de $\mathrm{NO}_{x}$ por tipo de combustível

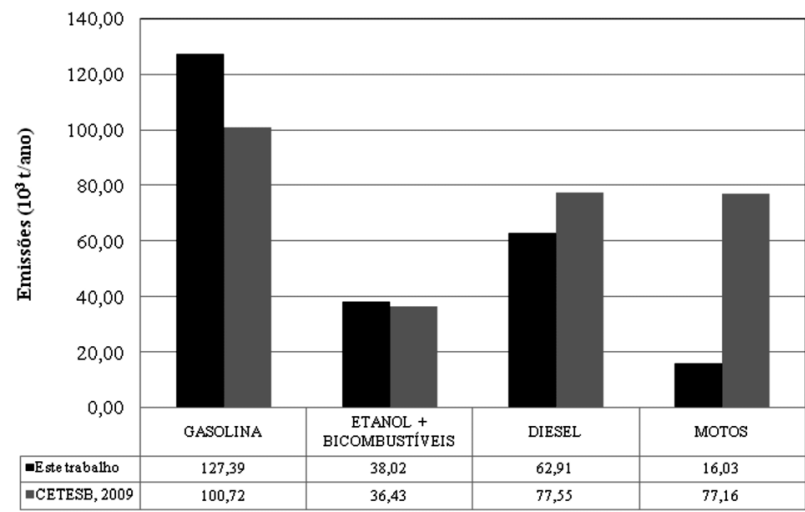

Figura 3. Comparativo das emissões de CO por tipo de combustível

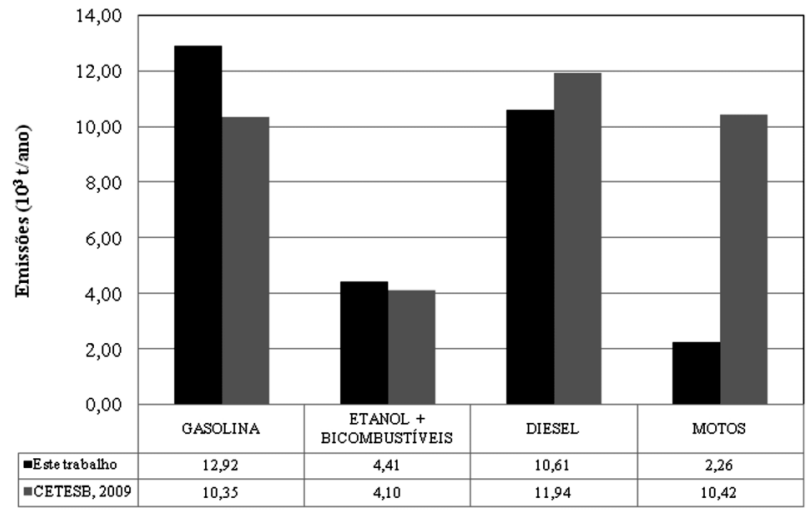

Figura 4. Comparativo das emissões de HC por tipo de combustivel

De forma geral, verifica-se que a comparação evidencia os diferentes métodos empregados em ambos os inventários. Para veículos a gasolina ocorreu uma diferença de cerca de $30 \%$ entre os valores de emissões de $\mathrm{CO}$ e $\mathrm{HC}$ deste trabalho e os da CETESB. Já para veículos a etanol e bicombustíveis, os resultados de ambos os trabalhos foram muito semelhantes, com diferenças inferiores a $10 \%$.

Pode-se observar na Figura 2 que os resultados deste trabalho e os da CETESB são muito próximos, principalmente para as emissões de veículos a gasolina, a etanol e bicombustíveis (diferenças de 17 e $9 \%$, respectivamente). Isto se deve principalmente ao fato de o fator de deterioração considerado para este poluente ser igual a 1,0 neste trabalho. Como o inventário da CETESB não considera este fator, então os resultados obtidos foram similares. As principais diferenças nas emissões de $\mathrm{NO}_{\mathrm{x}}$ ocorreram para veículos a diesel e motocicletas. Para estas categorias de veículos foram consideradas reduções na quilometragem média anual percorrida com o aumento da idade do veículo, o que não é considerado pela CETESB.

Para veículos movidos a gasolina foram observadas emissões de $\mathrm{CO}$ e HC superiores aos valores da CETESB. Isto mostra a dependência das emissões com o fator de deterioração e também com a redução da quilometragem média anual percorrida. $\mathrm{O}$ fator de deterioração aumenta as emissões e a variação da quilometragem média anual percorrida reduz as emissões. No cômputo geral, as emissões apresentam-se com diferença de 30\% das emissões da CETESB, mostrando que a metodologia da agência, além de ser menos detalhada, apresenta resultados mais conservadores.

Com relação aos veículos a etanol e bicombustíveis foram encontrados resultados de emissões de $\mathrm{CO}$ e $\mathrm{HC}$ muito semelhantes aos da CETESB, mostrando que, para estes tipos de veículos, as diferenças para mais, devido ao fator de deterioração, e para menos, devido à variação da quilometragem média anual percorrida, acabam sendo aproximadamente iguais. Isto é devido à menor idade da maior parte dos veículos movidos a etanol e dos veículos bicombustíveis.

Para veículos movidos a diesel as emissões de $\mathrm{CO}$ e HC também se mostraram menores que as da CETESB, devido à diferença na quilometragem média anual percorrida, assim como nas emissões de $\mathrm{NO}_{\mathrm{x}}$.

Para motocicletas ocorreu uma grande diferença entre as emissões de $\mathrm{CO}$ e HC calculadas por este trabalho com os resultados apresentados pela CETESB. Esta diferença é devida aos fatores de emissão utilizados, pois aqui foram consideradas somente motocicletas nacionais com 150 cilindradas ou menos, e também pela redução da quilometragem média anual percorrida.

As emissões veiculares calculadas também foram comparadas com as emissões industriais da RMC publicadas pela CETESB.$^{9}$ Os resultados são apresentados na Tabela 4 .

Tabela 4. Comparativo entre as emissões veiculares e industriais da RMC

\begin{tabular}{lcccc}
\hline \multirow{2}{*}{ Tipo } & \multicolumn{4}{c}{ Emissões (t/ano) } \\
\cline { 2 - 5 } & $\mathrm{CO}$ & $\mathrm{HC}$ & $\mathrm{NO}_{\mathrm{x}}$ & $\mathrm{MP}$ \\
\hline Veiculares & 244,35 & 30,21 & 46,35 & 2,26 \\
Industriais & 2,54 & 6,39 & 10,74 & 4,56 \\
\hline Total & $\mathbf{2 4 6 , 8 9}$ & $\mathbf{3 6 , 6 0}$ & $\mathbf{5 7 , 0 9}$ & $\mathbf{6 , 8 2}$ \\
\hline
\end{tabular}

Como se pode ver na Tabela 4, os veículos são responsáveis pela maior parte dos poluentes emitidos na RMC. Para os poluentes $\mathrm{CO}, \mathrm{HC}$ e $\mathrm{NO}_{x}$ as emissões veiculares correspondem a 99,0; 82,5 e $81,2 \%$ das emissões da RMC, respectivamente. Somente as emissões de MP são predominantemente industriais nesta região, sendo que as emissões veiculares correspondem a $33,2 \%$ das emissões. Porém, este número pode ser realmente maior, pois neste trabalho não foram consideradas emissões de MP de veículos a gasolina, etanol, bicombustível e motocicletas, pois não existem na literatura dados de fatores de emissão para estas categorias de veículos. Também existem emissões relativas a desgaste de pneus, lonas e discos de freio, que não foram contabilizadas.

\section{CONCLUSÕES}

A partir de dados oficiais de órgãos governamentais foi possível coletar informações para a realização do inventário de emissões de fontes móveis da RMC. Os resultados mostram que o inventário obtido é mais detalhado, em alguns aspectos, que o inventário da CETESB, 
demonstrando que é possível se obter um inventário de emissões adequado à realidade utilizando a abordagem bottom-up, mesmo não dispondo de dados específicos da região de estudo. Para os veículos movidos a gasolina, etanol e bicombustíveis foram obtidos bons resultados quando comparados aos dados da CETESB. Para as emissões de veículos a diesel e motocicletas seria necessário um refinamento com relação às quilometragens médias anuais percorridas, para se obter resultados mais exatos. Para motocicletas acredita-se que haja uma diferença na quilometragem média anual percorrida considerada, pois atualmente grande parte dos motociclistas utiliza este tipo de veículo para entregas de produtos e outros serviços, aumentando muito a quilometragem percorrida e, consequentemente, as emissões.

Além disso, foi mostrado que as emissões veiculares da RMC, principalmente de $\mathrm{CO}, \mathrm{HC}$ e $\mathrm{NO}_{x}$, representam mais de $80 \%$ das emissões totais da região.

Como resultado final, o inventário mostra que para melhorar a qualidade do ar na região devem ser controladas as emissões veiculares, principalmente para automóveis, instituindo programas de inspeção e manutenção periódica dos veículos, principalmente dos veículos antigos, melhorando a tecnologia de veículos novos e melhorando o transporte público.

\section{REFERÊNCIAS}

1. http://www.ibge.gov.br/cidadesat/topwindow.htm?1, acessada em Junho 2011.
2. Curtis, L.; Rea, W.; Smith-Willis, P.; Fenyves, E.; Pan, Y.; Environ. Int. 2006, 32, 815 .

3. Fundação Estadual de Engenharia do Meio Ambiente, Departamento de Planejamento Ambiental, Relatório da Divisão de Qualidade do Ar, Rio de Janeiro, 2004.

4. Lyra, D. G. P.; Tese de Doutorado, Universidade Estadual de Campinas, Brasil, 2008

5. Teixeira, E. C.; Feltes, S.; Santana, E. R. R.; Quim. Nova 2008, 31, 244.

6. Rangel, M. C.; Carvalho, M. F. A.; Quim. Nova 2003, 26, 265.

7. http://ceapla2.rc.unesp.br/atlas/regiaoadministrativa.pdf, acessada em Junho 2011.

8. Companhia Ambiental do Estado de São Paulo - CETESB, Relatórios, 2001 a 2005.

9. Companhia Ambiental do Estado de São Paulo - CETESB, Relatório, 2008.

10. http://www.detran.sp.gov.br/frota/frota_ano.asp, acessada em Junho 2011.

11. Associação Nacional dos Fabricantes de Veículos Automotores ANFAVEA, Relatório, 2009.

12. Companhia Ambiental do Estado de São Paulo - CETESB, Relatório, 2009.

13. http://www.issrc.org/ive/downloads/reports/SaoPauloBrazil.pdf, acessada em Junho 2011.

14. Murgel, E. M.; Szwarc, A.; Santos, M. D. S. R.; Branco, G. M. B.; Carvalho, H.; Eng. Sanit. 1981, 26, apud U.S. EPA, 1981.

15. United States Environmental Protection Agency, Relatório, 1981. 